\title{
Retraction Note to: An environmentally benign one pot synthesis of substituted quinolines catalysed by fluoroboric acid based ionic liquid
}

by A Rajendran, C Karthikeyan, K Rajathi and D Ragupathy, J. Chem. Sci. Vol. 124, No. 4, July 2012, pp. 877-881

Instance of Plagiarism in Journal of Chemical Sciences and withdrawal of published article

The Journal of Chemical Sciences office received a complaint from an alert reader to the effect that the paper 'An environmentally benign one pot synthesis of substituted quinolines catalysed by fluoroboric acid based ionic liquid' by A Rajendran, C Karthikeyan, K Rajathi and D Ragupathy, published in J. Chem. Sci. Vol. 124, No. 4, July 2012, pp. 877-881 is a plagiarized version of an earlier article published in the Indian Journal of Chemistry 'An environmentally benign indium (III) chloride catalysed one-pot synthesis of quinolines' by Mazaahir Kidwai, Vikas Bansal, Neeraj Kumar Mishra and Divya (Vol. 48B, May 2009, pp. 746-748). The 'results and discussion' part of the J. Chem. Sci. paper contained exactly the same sentences, the same tables of results with the same yields as those of the article published in 2009; only the catalyst $\mathrm{InCl}_{3}$ was changed to $\left[\mathrm{Et}_{3} \mathrm{NH}\right]+\left[\mathrm{BF}_{4}\right]$. The bibliographic references 2 to 6 were also the same.

The Editor has ascertained from the corresponding author, Dr. A. Rajendran that there has indeed been a clear case of plagiarism. Dr Rajendran has requested that the article be withdrawn from the journal.

Accordingly, and as per the Academy policy on plagiarism, it has been decided to withdraw the article published by Rajendran et al. in the Journal of Chemical Sciences and remove the article from the websites of the Academy and Springer.

The Editorial Board takes a serious view of acts of plagiarism in the journal and is committed to take all necessary steps to prevent such acts.

S S Krishnamurthy

Editor,

Journal of Chemical Sciences e-mail: chemsci@ias.ernet.in 